\title{
|||||||||||||||||||||||||||||||||||||||||||||||||||||||||||||||||||.
}

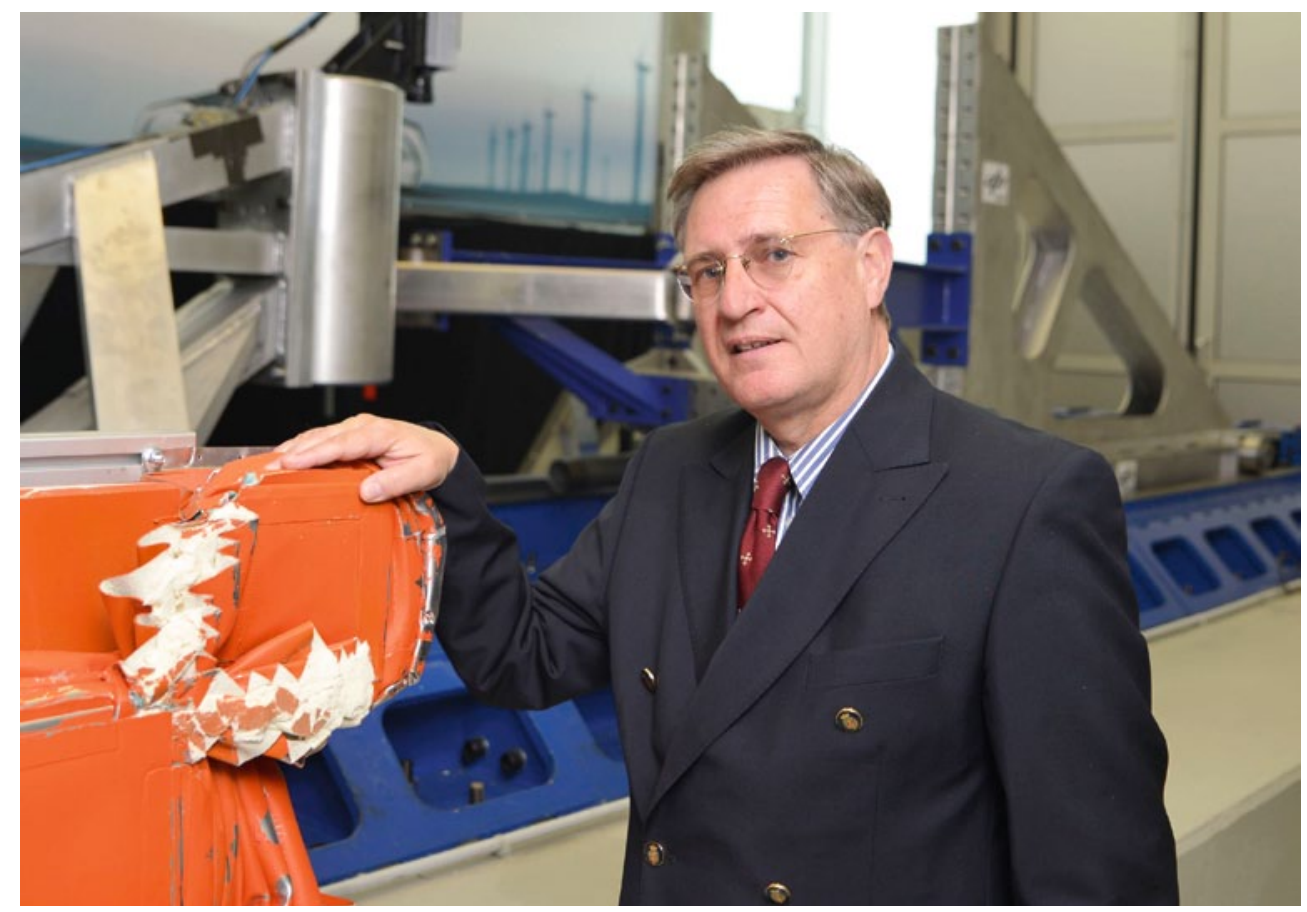

PROF. DR.-ING.

HORST E. FRIEDRICH

Direktor des Instituts

für Fahrzeugkonzepte,

DLR, Stuttgart

\section{LUST AN WERKSTOFFEN}

Die Vielfalt zukünftiger Fahrzeug- und Antriebskonzepte scheint vorgezeichnet. In unseren Szenarien zeigen sich die Verkaufszahlen von Hybriden im deutschen Markt bis 2020 stabil und PHEV/EREV bereits im Jahr 2025 mit Marktanteilen von $15 \%$ und teilweise mehr. Anders rein elektrische Fahrzeuge: Trotz unbestrittener Sinnhaftigkeit im urbanen Nutzenprofil sehen wir auch bis 2030 den Anteil bei nicht mehr als $20 \%$ BEV und 15 \% FCEV. Sicher ist: Die Anzahl der Fragestellungen in Forschung und Vorentwicklung wird wachsen. Wie wird die Vielfalt wirtschaftlich und nachhaltig darstellbar sein?

Eines scheint klar: Es wird über viele Jahrzehnte mehrere Antriebsarchitekturen nebeneinander geben, und ihnen gemeinsam sind mindestens zwei Anforderungen: Als erstes müssen die Fahrzeuge stärker modularisiert werden, um kostenattraktiv zu sein. Und zweitens wird höchste Energieeffizienz obligatorisch. Letzteres führt zum Leichtbau mit Werkstoffen und Bauweisen, die Funktionsintegration und adaptierbare Eigenschaften ermöglichen.

Für den strukturell anspruchsvollen Vorderwagen bietet ein bei uns entwickeltes, leichtmetallintensives Konzept Gewichtsvorteile von 20 bis $25 \%$ gegenüber einer Stahlreferenz. Es nutzt Schälrohrabsorber zur gezielten Einstellbarkeit der Crashkennung für unterschiedliche Antriebsvarianten.

Bislang weitgehend ungenutzt sind Sandwichbauweisen, die thermische Isolation oder lokal angepasste Crasheigenschaften bei niedrigem Gewicht bieten. Unsere Forschung zeigt das
Leichtbaupotenzial einer Karosserie für ein zweisitziges L7eFahrzeug, die bei einem Gewicht von 90 kg im Front- und Pfahlcrash ähnlich sicher ist wie ein Mittelklassefahrzeug.

Innovative Fahrwerks- und Antriebskonzepte nutzen gezielt die Integration von radindividuellem Antrieb, Form- und Werkstoffleichtbau. Die Position der elektrischen Maschine ermöglicht eine hohe Modularisierbarkeit der Antriebsleistung und neue Designfreiheiten sowie eine Gewichtsersparnis von $30 \%$, indem radführende Massen reduziert werden.

CFK liegt im Trend - trotzdem: Leichtmetallgusskomponenten sind bewährt, kostenattraktiv und schneiden in der $\mathrm{CO}_{2}^{-}$ Bilanz gut ab. Diese hängt allerdings von Herkunft und Prozesstechnik ab. Der IMA zufolge hat sich die Bilanz der Magnesiumherstellung in China nun deutlich verbessert. Man geht von $26 \mathrm{~kg} \mathrm{CO}_{2}$ pro kg Primär-Mg aus; via Elektrolyse sinkt der Wert auf $14 \mathrm{~kg}$. Zum Vergleich: Die Treibhausgasemissionen für Aluminium liegen im Durchschnitt bei 12,5 kg, und Magnesiumbauteile können bis zu 25 \% leichter sein als Aluminium gleicher Funktion.

All dies macht Lust, Werkstoffe genauer zu erforschen: von Strukturkonzepten bis zur Funktionsintegration, von der Gewichtsoptimierung bis zu neuen Materialien. Erfahren Sie mehr über die Königsdisziplin Werkstofftechnik bei der fünften Fachtagung „Werkstoffe im Automobil“ von ATZlive, dem Branchentreff unter dem Motto „Neue Materiallösungen und Konzepte im Dialog“ am 5. und 6. November 2014 in Stuttgart. 